

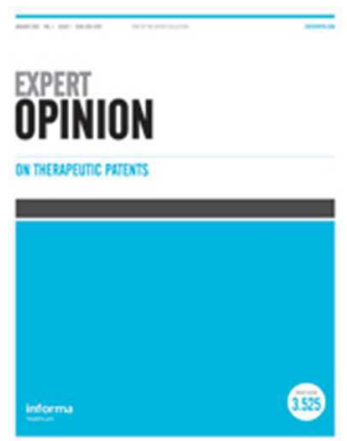

Please download and read the Referee Guidelines

\section{Pleiotropic mechanisms of action of perhexiline in heart failure}

\begin{tabular}{|r|l|}
\hline Journal: & Expert Opinion On Therapeutic Patents \\
\hline Manuscript ID & EOTP-2016-0016.R1 \\
\hline Manuscript Type: & Review \\
\hline Keywords: & $\begin{array}{l}\text { Heart, Metabolism, Perhexiline, Carnitine palmitoyltransferase 1, Fatty acid } \\
\text { oxidation, Glucose utilisation, Tissue accumulation }\end{array}$ \\
\hline \multicolumn{2}{|c}{} \\
\hline
\end{tabular}

SCHOLARONE ${ }^{\text {m }}$

Manuscripts 
1

2

3

4

5

6

7

8

9

10

11

12

13

14

15

16

17

18

19

20

21

22

23

24

25

26

27

28

29

30

31

32

33

34

35

36

37

38

39

40

41

42

43

44

45

46

47

48

49

50

51

52

53

54

55

56

57

58

59

60
Review

Pleiotropic mechanisms of action of perhexiline in heart failure

\author{
Christopher H. George ${ }^{1}$, Alice N. Mitchell ${ }^{1}$, Ryan Preece ${ }^{1}$, Mark L. Bannister ${ }^{1}$, Zaheer \\ Yousef $^{1}$ \\ ${ }^{1}$ Wales Heart Research Institute, School of Medicine, Cardiff University, Cardiff, Wales, UK.
}

\section{Corresponding author:}

Christopher H. George

Wales Heart Research Institute, School of Medicine

Heath Park Campus, Cardiff University

Cardiff, Wales, UK CF14 4XN

Tel: 02920744431

E-mail: georgech@cf.ac.uk 


\begin{abstract}
Introduction: The re-purposing of the anti-anginal drug perhexiline (PHX) has resulted in symptomatic improvements in heart failure (HF) patients. The inhibition of carnitine palmitoyltransferase-1 (CPT-1) has been proposed as the primary mechanism underlying the therapeutic benefit of PHX. This hypothesis is contentious.

Areas covered: We reviewed the primary literature and patent landscape of PHX from its initial development in the 1960 s through to its emergence as a drug beneficial for HF. We focused on its physico-chemistry, molecular targets, tissue accumulation and clinical dosing. Expert opinion: Dogma that the beneficial effects of $\mathrm{PHX}$ are due primarily to potent myocardial CPT-1 inhibition is not supported by the literature and all available evidence point to it being extremely unlikely that the major effects of $\mathrm{PHX}$ occur via this mechanism. In vivo $\mathrm{PHX}$ is much more likely to be an inhibitor of surface membrane ion channels and also to have effects on other components of cellular metabolism and reactive oxygen species (ROS) generation across the cardiovascular system. However, the possibility that minor effects of PHX on CPT-1 underpin disproportionately large effects on myocardial function cannot be entirely excluded, especially given the massive accumulation of the drug in heart tissue.
\end{abstract}

Keywords: perhexiline, carnitine palmitoyltransferase, heart failure, metabolism, modulation, therapy

URL: http://mc.manuscriptcentral.com/eotp Email: Julia.Galway-Witham@informa.com² 


\section{Article highlights}

- In contrast to recent dogma, we propose that it is unlikely that the therapeutic benefit of perhexiline in patients with HF is due, in large part, to the inhibition of CPT-1.

- All available data suggests that PHX is a drug of low potency, low specificity and low selectivity that interacts with multiple surface membrane ion channels and other intracellular components that impinge on cellular metabolism and the generation of reactive oxygen species (ROS).

- The possibility that minor effects of PHX on CPT-1 underpin disproportionately large effects on myocardial function cannot be excluded, especially given the massive accumulation of $\mathrm{PHX}$ in myocardial tissue.

- A scheme is described that considers the pleiotropic effects of PHX via the inhibition of surface membrane ion channels and its accumulation in mitochondrial membranes.

- The combined action of PHX on multiple targets throughout the cardiovascular system probably underpins the symptomatic improvements in HF patients. 


\section{(1) Introduction- new therapies for heart failure (HF).}

As defined by Yancy and colleagues "HF is a complex clinical syndrome that results from any structural or functional impairment of ventricular filling or ejection of blood". ${ }^{1}$ It is a global epidemic, affecting $10 \%$ of individuals over the age of 65 years and its clinical progression results in mortality of $50 \%$ within 4 years of diagnosis. ${ }^{1}$ Contemporary approaches, which aim to correct left ventricular ejection fraction (LVEF) and halt or normalize the progression of myocardial dysfunction are sub-optimal and involve the modulation of neurohumoral targets including $\beta$-adrenergic ( $\beta$-AR) blockers, suppression of the renin-angiotensinaldosterone (RAA) system (angiotensin II receptor (ATIIR), angiotensin-converting enzyme (ACE), aldosterone antagonism), vasodilators and diuretics. Whilst these conventional therapies primarily modulate upstream regulators of the circulatory system, there are newer strategies that aim to target more 'myocardially-focused' elements including the drivers of progressive contractile and arrhythmogenic events that occur within cardiac cells $s^{2-5}$ and even approaches that replace or repair damaged myocardium. ${ }^{6}$

We have previously described normal myocardial cell signaling in terms of the synchronization of coupled systems. ${ }^{7-9}$ For example, there is functional integration between cellular ion fluxes and metabolism in which the dynamic cycling of intracellular $\mathrm{Ca}^{2+}$ is critically modulated by ATP-dependent processes, and many events in ATP synthesis are $\mathrm{Ca}^{2+}$-dependent. Consequently, the functional deterioration of the myocardium in long-term cardiac diseases such as HF is associated with the progressive desynchronization within and between numerous linked processes. Using the example above, disease-linked derangement in $\mathrm{Ca}^{2+}$ signaling, which is considered a major feature of HF pathogenesis, impacts on ATP bioavailability and vice versa. ${ }^{7,8}$

If we consider then that approaches that aim to correct HF-linked $\mathrm{Ca}^{2+}$ signaling dysfunction $^{7,8,10-14}$ may positively influence other 'linked' systems such as metabolism, there is substantial merit in developing new therapies that alter cellular metabolism with a view to rescuing cellular $\mathrm{Ca}^{2+}$ handling. An emergent approach to normalizing cardiac performance in HF therefore is the direct modulation of the myocardial metabolic state and drugs that 
promote a switch in substrate utilization from fatty acid oxidation (FAO) to glycolysis (socalled 'metabolic modulators') are keenly sought. ${ }^{15-18}$

Important problems in developing new therapeutic approaches though include the limitations of rational drug design and sometimes prohibitory regulatory and financial barriers which have led to creative solutions for finding new niches for existing drugs in the clinical landscape., 19-23 'Repositioning', 'repurposing' and 'reappropriating' have become buzzwords in the contemporary drug development framework.

In this article, we consider some of these issues relating to perhexiline (PHX; 2-(2,2dicyclohexylethyl)piperidine), a drug reappropriated from the treatment of angina pectoris (AP) and reported to be a clinically useful drug in the management of HF. The history of $\mathrm{PHX}$, from its initial development as an L-type $\mathrm{Ca}^{2+}$ channel blocker ${ }^{24-29}$, its efficacy in $\mathrm{AP}^{29-}$ 35 , its contraindications, withdrawals and now its emergence in treating HF has been comprehensively reviewed previously. ${ }^{15,18,36}$ However, its mechanism of action remains contentious and here we consider, with specific reference to the patent landscape, how the apparent disconnect between the measureable clinical benefits of PHX in HF and the molecular underpinnings of its actions can be reconciled.

\section{(2) Promoting the shift from FAO to glycolysis in HF - the rationale for carnitine palmitoyl transferase (CPT) inhibition.}

The hallmark metabolic dysfunction in HF is the intrinsic shift from FAO (aerobic) to glucose (anaerobic) metabolism. ${ }^{37-42}$ This transition is likely the consequence of a lack of adequate cardiac tissue oxygenation in the diseased state- although this is questionable in nonischaemic $\mathrm{HF}(\mathrm{DCM})^{43}$ - but it may, to some extent, represent an adaptatory mechanism to preserve myocardial function. Although glucose metabolism yields much less ATP than FAO (a theoretical yield of 38 moles ATP for the complete oxidation of glucose versus 129 moles ATP per mole of palmitate) $)^{44}$, it is a more oxygen efficient mode of energy production yielding 3.17 moles ATP/moles atomic oxygen versus 2.8 moles of ATP/moles atomic oxygen for FAO of palmitate..$^{44}$ Approaches that aim to promote this 'oxygen sparing' effect 
would also be coupled to the reduced flux of intermediates through the tricarboxylic acid (TCA or Krebs cycle) which would decrease the generation of reactive oxygen species (ROS) and minimize lactate production thereby preventing acidosis (Figure 1). Potentially, the combined effects of reduced $\mathrm{ROS}$ and normalized $\mathrm{pH}$ may contribute more to the beneficial effect of 'metabolic modulation' than considerations regarding the lower net yield of ATP. Since metabolism is enmeshed with numerous other cellular process (e.g. mTORC1/AMPK-mediated nutrient sensing modules involved in cell growth and autophagy $)^{45-48}$, there are other considerations for 'metabolic modulation' beyond ATP synthesis and consumption and energy substrate utilization.

Singh and colleagues have recently reviewed candidates for therapeutic metabolic modulation including the TCA cycle, pyruvate dehydrogenase (PDH), malonyl CoAdecarboxylase (MCD), fatty acid oxidation (FAO), insulin sensitivity and carnitine palmitoyltransferase (CPT-1). ${ }^{18}$ Of these, it is CPT-1, an outer-mitochondrial membraneresident enzyme, that has received the most attention. There are three isoforms of CPT-1 (1A, 1B and 1C); CPT1A and B share $63 \%$ sequence homology and are abundantly expressed in a wide variety of tissues, whereas CPT-1C is restricted to the brain. ${ }^{49} \mathrm{CPT}-1 \mathrm{~B}$ is the predominant isoform in the heart and exhibits a lower affinity for its substrate carnitine than CPT-1A (approximately 15 -fold) but is more sensitive to inhibition by the endogenous inhibitor malonyl co-A inhibition than CPT1A. ${ }^{49}$ CPT-1 catalyzes the formation of acyl carnitine, via the transfer of the acyl group of a long-chain fatty acyl-CoA from coenzyme A to carnitine ${ }^{50}$. Acyl carnitine subsequently transfers from the cytosol into the mitochondrial inter-membrane space to undergo CPT-2-catalyzed conversion back to acyl-CoA which undergoes catabolic beta-oxidation in the mitochondrial matrix to yield acetyl-CoA which then enters the TCA cycle (Figure 1). In principle therefore, CPT-1 inhibition, which in situ is mediated by of malonyl Co-A levels (Figure 1), reduces mitochondrial import and oxidation of fatty acids, promotes glycolysis via reduced acetyl-CoA production and decreases ROS and lactate accumulation (Figure 1) albeit at the expense of ATP production. 
One approach to therapeutically target CPT-1 activity is the development of heterocyclic and piperidine compounds that inhibit malonyl-CoA decarboxylase (MCD) which leads to an accumulation of malonyl-Co $\mathrm{A}^{51,52}$, the endogenous inhibitor of CPT- 1 in vivo (Figure 1). ${ }^{53}$ We return to the subject of malonyl-CoA inhibition of CPT-1, and the implications for adjunctive PHX-mediated inhibition, in section 4.

However, in the context of treating chronic myocardial dysfunction, it is the direct pharmacologic inhibition of CPT-1 that has captured the imagination. In a compelling series of clinical studies, $\mathrm{PHX}$ (hailed as the 'forerunner of metabolic agents ${ }^{\text {,16 }}$ ) has been shown to produce beneficial effects in patients with refractory HF symptoms despite otherwise optimal medical therapy ${ }^{54}$, symptomatic hypertrophic cardiomyopathy $(\mathrm{HCM})^{55}$, and non-ischaemic dilated cardiomyopathy (DCM). ${ }^{56}$ Such symptomatic improvements include reduced New York Heart Association (NYHA) classification of disease severity ${ }^{54,55}$, increased peak oxygen uptake $\left(\mathrm{VO}_{2} \max \right)^{54,55}$, improvements in quality-of-life scores ${ }^{54,56,57}$ and six-minute walk tests ${ }^{57}$. Whether these functional benefits are dependent on improved myocardial function (e.g. left ventricular ejection fraction; see ${ }^{54}$ vs. ${ }^{56}$ ), or interestingly skeletal muscle function ${ }^{54}$, has yet to be fully established. Moreover, although these investigations evidence beneficial changes in the phosphocreatine/ATP ratio which suggest generalized improvements in cardiac energetics, in their study of DCM patients Beadle et al. failed to find evidence of altered cardiac substrate utilization ${ }^{56}$. This finding is at odds with the principal dogma of earlier studies on $\mathrm{PHX}$ that its main effect is to promote the shift from FAO to glycolysis. ${ }^{25,29,58,59}$ It is necessary therefore to harmonize the therapeutic benefit of PHX with its mechanism of action and in sections 3 to 6 we address this issue by reference to the patent literature and the physico-chemical determinants of CPT-1 inhibition.

\section{(3) PHX, CPT-1 and the patent landscape.}

Notwithstanding some of the disparate effects of PHX in patients with different forms of chronic heart disease ${ }^{54-56}$, an important question is to what extent does CPT-1 inhibition contribute to the clinical improvement measured in these patients. The first patent relating to 
PHX and CPT-1 was filed by Horowitz and Kennedy ${ }^{60}$ and sought to protect the use of a screening assay for discriminating compounds on the basis of CPT-1 inhibition. Such compounds were proposed to be useful in treating 'ischaemic conditions'.

On the basis of demonstrating improved clinical endpoints in PHX-treated patients, Frenneaux and colleagues have filed a suite of patents pertaining to its efficacy in ischaemic and non-ischaemic $\mathrm{HF}^{61}$, HF with preserved ejection fraction (HFpEF) ${ }^{62}$ and hypertrophic cardiomyopathy (HCM). ${ }^{63}$ These patents all include the phrase "Perhexiline (2-(2,2dicyclohexylethyl)piperidine) is a known anti-anginal agent that operates principally by virtue of its ability to shift metabolism in the heart from free fatty acid metabolism to glucose, which is more energy efficient", but it is striking that none of these patents claim that the clinical benefit of PHX is because of CPT-1 inhibition.

However, the CPT-1-centricity of the proposed mechanism of PHX action persists and a recent patent filing from the University of Aberdeen seeks to protect intellectual property (IP) around a fluorinated PHX-derivative useful for treating a very broad range of "disorders that are ameliorated by the inhibition of carnitine palmitoyltransferase......" ${ }^{64}$

With regard to the progression of HF being a consequence of the deterioration of linked systems (see section 1), it is interesting to note that the patent on PHX effect in ischaemic and non-ischaemic $\mathrm{HF}^{61}$ states that "metabolic manipulation with $\mathrm{PHX}$ is effective in modifying not an inciting influence, but rather the common programme of the chronic heart failure". It is plausible therefore that the metabolic dysfunction in HF is secondary to the abnormality in some other linked system and that PHX may be useful in modifying the chronic metabolic remodelling associated with HF progression and not in preventing disease onset.

\section{(4) Is PHX a physiologically relevant CPT-1 inhibitor?}

The symptomatic improvement in HF following PHX administration has been linked to a broad range of phenomenological descriptions including cGMP-dependent potentiation of platelet sensitivity to $\mathrm{NO}^{32,35,65}$, vasodilatory effects ${ }^{66,67}$, positive inotropic actions via 
troponin- $\mathrm{C}^{68}$, circulating levels of $\operatorname{ROS}^{69}$ and insulin sensitization. ${ }^{70}$ However, assigning the molecular target(s) of PHX that underlies these phenomena has proved more difficult.

The patent filing of Horowitz and Kennedy ${ }^{60}$, together with the companion paper from the same group ${ }^{71}$, used an in vitro (intact) mitochondrial assay to robustly make the case that PHX (and also amiodarone) was a CPT-1 inhibitor. It was here that the concept that the "major biochemical basis of the anti-ischaemic effect of PHX is inhibition of CPT-1" was born. Measuring drug $\mathrm{IC}_{50}$ values in this type of assay is prone to influence from several variables, including the levels of the protein in the tissue, local concentration of drug and the accessibility of its binding site (i.e. isolated mitochondrial preparations). To our knowledge, the binding affinity of PHX for CPT-1 has not been determined. We acknowledge that it is difficult to experimentally mimic in vitro the precise conditions that may be important determinants of drug-target interaction in vivo. Although we consider investigations using recombinant CPT isoforms expressed in methylotrophic Pichia pastoris yeast to constitute the most direct measurements of PHX-CPT interaction ${ }^{72,73}$, the likelihood of PHX binding multiple targets (1) makes it impossible at present to assign the relative contributions of $\mathrm{PHX}$ modulation of individual targets to the downstream effects. As has been noted previously, these issues relating to 'holistic' assessments of drug action are presently beyond the resolution of contemporary assays. ${ }^{22}$

On the basis of Kennedy's early work on CPT1 inhibition by $\mathrm{PHX}^{71}$, the review literature on $\mathrm{PHX}$ perpetuates the idea that the primary mechanism of action the drug is through CPT-1 inhibition (for example, "the identification of CPT-1 as perhexiline's major biochemical site of inhibition"15). Given the paucity of supporting data, the evidence base for this assertion is not convincing (Table 1).

$\mathrm{PHX}$ shares common properties with other $\mathrm{Na}^{+}-, \mathrm{K}^{+}$- and $\mathrm{Ca}^{2+}$ - ion channel blockers, many of which are recognized anti-arrhythmic drugs (Table 2), including its appreciable hydrophobicity and an ionizable nitrogen which is positively charged at neutral $\mathrm{pH}(7.4)$. In this regard, $\mathrm{PHX}$ is chemically different to etomoxir, which is an exemplar CPT inhibitor ${ }^{49}$ and in a quasi-exhaustive review of CPT inhibitor chemistry, PHX, oxfenicine (where the 
active metabolite is 4-hydroxyphenylglyoxylate (HPG)) and amiodarone were clearly categorized as "miscellaneous compound[s] reported to be CPT inhibitors". ${ }^{49}$ Ceccarelli et al. concluded that in view of PHX's extremely weak inhibition of CPT-1 it was "highly questionable that the effects are due to CPT1 inhibition". ${ }^{49}$ The chemical properties of PHX would also suggest relatively poor selectivity and specificity. ${ }^{74}$ This is corroborated by the data in Table 1 which emphasizes the multiplicity of PHX targets and importantly, all available data point to PHX exerting its least potent effect on CPT-1 (Table 1). However, it is recognized that functional pleiotropy (i.e. drug promiscuity), which we have previously considered as 'magic shotguns' versus 'magic bullets ${ }^{\text {,75 }}$, can be beneficial. ${ }^{76}$ This is discussed this further in section 7.

In consideration of the other reported targets of $\mathrm{PHX}$ (Table 1), the relevance of competitive inhibition of CPT-1 by PHX in situ (characterized by an $\mathrm{IC}_{50}$ of $77 \mu \mathrm{M}$ determined in isolated mitochondria membrane preparations ${ }^{71}$ ) may be questioned. Moreover, the inhibition of CPT-1 by malonyl-CoA is $10-100$ times more potent $\left(\mathrm{IC}_{50}\right.$ of $0.6-6.3 \mu \mathrm{M}$ depending on the local concentration of palmitoyl-CoA $(25 \mu \mathrm{M} \text { or } 150 \mu \mathrm{M} \text {, respectively) })^{77}$ with a recent ex vivo study suggesting that malonyl-CoA produces a $33 \%$ inhibition of CPT-1 activity in resting (non-stimulated) muscle. ${ }^{77}$ However, it may be important in vivo that the actions of PHX on CPT-1 are mechanistically different to those of malonyl co-A and oxfenicine $\left(\mathrm{IC}_{50}\right.$ of $\mathrm{CPT}-1$ inhibition $\left.=11 \mu \mathrm{M}^{78}\right)$ and it has been suggested that $\mathrm{PHX}$ acts at a protected mitochondrial site not amenable to proteolysis i.e. in the plane of the membrane. ${ }^{15}$, 71,79 It is also intriguing that the specific counterion used in the preparation of the clinical formulation of a drug may have a profound impact on its physico-chemical properties, including $\log \mathrm{P} .{ }^{80}$ This is especially pertinent for maleate which has been shown to directly influence cellular metabolism via promoting the utilization of glucose and the accumulation of fatty acids. ${ }^{81,82}$ The contribution of the maleate 'counterion' to the effects attributable to PHX, especially in the context of altered metabolism, warrants further investigation. ${ }^{83}$

Recent proteomic and metabolic studies have corroborated a complex effect of PHX on metabolism. ${ }^{84,85}$ In a study of mice treated for 4 weeks at steady-state PHX plasma 
concentration, Yin and colleagues reported the activation of the pyruvate dehydrogenase complex (PDH) (Figure 1) and a "rebalancing of carbon and nucleotide phosphate fluxes, fuelled by increased lactate and amino acid uptake, to increase metabolic flexibility and maintain cardiac output". ${ }^{84}$ Furthermore, Ceccarelli determined a greater potency of PHX on ketone body (KB) generation and beta-oxidation (FAO) inhibition in rat and human hepatocytes $\left(\mathrm{IC}_{50}=14.8\right.$ and $22.4 \mu \mathrm{M}$, respectively $)$ than on CPT-1 inhibition $\left(\mathrm{IC}_{50}>100\right.$ $\mu \mathrm{M}) .{ }^{49}$ Together these data advance the idea that the therapeutic effects of PHX may be due, in some part to bona fide metabolic modulation, but the notion of $\mathrm{PHX}$ being a potent inhibitor of CPT-1 needs further evaluation.

To this end, the effects of PHX on reduced ROS may be more attributable to direct inhibition of NADPH oxidase (NOX2) rather than effects on cardiac energetics per se. ${ }^{86}$ Also, Unger and colleagues reported that in non-ischaemic working rat hearts, "perhexiline increases myocardial efficiency by a mechanism(s) that is largely or entirely independent of its effects on CPT". ${ }^{87}$

\section{(5) PHX metabolism, physico-chemistry and tissue accumulation}

A well-known consequence of longer term (unmonitored) PHX administration (typically $>3$ months $)^{88}$ is lipidosis-induced hepato- and neuro-toxicity, hypoglycaemia and weight loss. ${ }^{31}$, ${ }^{34,89-94}$ However, there is now a more complete understanding of the risk factors predisposing individuals to adverse effects, including patient-specific CYP2D6 status. ${ }^{95-98}$ Oxidative metabolism of PHX produces mono- and di-hydroxylated metabolites. The predominant metabolite detected in plasma - cis-4 hydroxyperhexiline - is found at concentrations higher than PHX.99, 100 Those individuals with CYP2D6 insufficiency ('poor metabolizers') have a reduced capacity to form this metabolite ${ }^{101}$ and thus PHX is contraindicated in these individuals. This association between drug chirality and toxicity is also important $\mathrm{t}^{99,100,102}$ since there is reported stereoselectivity of (+) and (-) enantiomers to metabolism. ${ }^{95,100,101}$ The asymmetry of the $\mathrm{C} 2$ of the piperidine ring means that $\mathrm{PHX}$ is administered as a racemic mixture of $(+)$ and (-) enantiomers. The (+)-PHX enantiomer is 
cleared more slowly from the plasma $a^{103-105}$ and is associated with a more pronounced toxicity profile. ${ }^{104,106}$ Sallustio's recent patent on the use of (-)-PHX seeks to negate the issue of toxicity and other problems possibly linked to the complex mixture of different stereoisomers and metabolites of unknown efficacy arising from administration of the unresolved racemic mixture. ${ }^{106,107}$

Awareness of the issues considered above, coupled with optimised dosing regimens and plasma drug monitoring to maintain a therapeutic range between $0.15-0.6 \mathrm{mg} / \mathrm{L}$ (approximately $0.5-2 \mu \mathrm{M})^{108-110}$, have led to the re-introduction of PHX in the UK on a named patient basis. However, phospholipidosis-linked toxicity (similar to that observed with chronic amiodarone exposure $)^{111}$ raises the issue of accumulation in tissues which requires further consideration of $\mathrm{PHX}$ from a physico-chemical perspective.

$\mathrm{PHX}$ is very poorly water soluble (limit of solubility of $0.0608 \mathrm{mg} / \mathrm{L}$; approximately $0.2 \mu \mathrm{M})$ and highly lipophilic- the logP, the octanol-water partition coefficient used as a measure of lipophilicity is 6.2 , comparable to that of amiodarone, a drug for which membrane accumulation is a causal factor in its serious adverse effects (Table 2). Given the very low water solubility of $\mathrm{PHX}$, at safe clinical dosing levels (i.e. plasma concentration of drug between 0.15 and $0.6 \mathrm{mg} / \mathrm{L})$, the ratio of $[\mathrm{PHX}]_{\text {unbound }}$ to $[\mathrm{PHX}]_{\text {bound }}$ would be approximately $40: 60 \%$ and 10:90\%, respectively. Importantly then, since under normal (monitored) dosing conditions PHX would already be at its limit of solubility, any increase in the concentration of PHX upwards of reportedly 'toxic' plasma levels of drug (i.e. $>0.6 \mathrm{mg} /$ L) would simply mean that more of the drug existed in a bound state in the plasma. The notion therefore that monitoring plasma levels of $\mathrm{PHX}$ does not give a true indication of drug distribution was recently confirmed by the remarkable finding of Drury and colleagues that the concentrations of PHX in human right atria and left ventricles were 6.0 and $10.0 \mathrm{mg} / \mathrm{kg}$, respectively- approximately 100- to 170- times higher than the amount of $\mathrm{PHX}$ unbound ('free') in the plasma. ${ }^{112}$ The massive accumulation of drug was corroborated by the same authors in a recent study. ${ }^{103}$ 
So how does PHX accumulate to such high levels in tissue? We describe the possible mechanisms that underpin accumulation of the drug in section 6 , but it is first necessary to consider the impact that drug ionization state will have on the modes of transfer across cellular membranes. The pKa of $\mathrm{PHX}$ is 10.58 so $99.9 \%$ of the drug would exist in the charged (cationic) form in the plasma at $\mathrm{pH} 7.4$. As discussed above then under therapeutic dosing regimens (i.e. at its limit of solubility of $0.06 \mathrm{mg} / \mathrm{L}$ ), effectively all of the drug would exist in the cationic form $(\approx 99.9 \%, 0.05994 \mathrm{mg} / \mathrm{L})$ with the neutral form present at just $0.00006 \mathrm{mg} / \mathrm{L}$. If the tiny amount of the neutral form of the drug $(\approx 60 \mathrm{ng} / \mathrm{L}$ in the plasma) was the only species able to transfer across the cell surface membrane, myocardial concentrations of the drug at 6 - $10 \mathrm{mg} / \mathrm{kg}{ }^{103,112}$ would establish an intracellular:plasma concentration gradient of $100,000: 1$. It is inconceivable that such massive accumulation could be supported by simple passive transfer of the neutral form of the drug from the plasma into cells, even if one considers that the neutral species that does partition across the surface membrane would be immediately protonated (to its cationic form) in the cellular environment (Figure 2). This therefore raises the likelihood that other factors contribute to the cellular accumulation of PHX. First, the peculiar hydrophobicity properties of PHX may promote the integration of the cationic species into the membranes. Second, and probably the most likely contributor to the cellular accumulation of $\mathrm{PHX}$, is that organic ion transporter proteins (TP) present in the surface membrane are likely involved in the active uptake of the cationic form of the drug into cells, as has been reported to occur with amiodarone, a drug with a very similar physico-chemical profile to $\mathrm{PHX} .^{113}$

\section{(6) Possible mechanisms of PHX accumulation in tissues.}

Some of the acute effects of PHX, at least in experimental systems, are rapidly reversible. In chick embryo ventricular cells, Barry et al. described the negative inotropic effect of PHX measured after a seven minute equilibration to reach steady state drug effects which was quickly reversed by washing out the drug. ${ }^{114}$ However, as described in section 5 , under 
conditions of clinical dosing it appears that the therapeutic (and in some cases the hazardous) effects of PHX are primarily mediated by longer term accumulation inside cells.

Figure 2 describes some of the mechanisms that may contribute to $\mathrm{PHX}$ accumulation in the myocardium. Any cellular accumulation would be dependent on factors that disturb the free equilibrium between the cells and plasma and thus the only way that the drug can accumulate to levels grossly in excess of the plasma concentration is if there is an intracellular binding target or the relatively stable association of the drug with lipid membranes. Consequently, the scenario depicted in Figure 2A which describes the loading of cytoplasm with high $[\mathrm{PHX}]_{\text {free }}$, and which may be commonly thought of as 'cytoplasmic accumulation', cannot occur. Also refuting the possibility that high cytoplasmic $[\mathrm{PHX}]_{\text {free }}$ (as depicted in Figure 2A) occurs in situ is that under these conditions the surface membrane $\mathrm{Na}^{+}-, \mathrm{K}^{+}-$and $\mathrm{Ca}^{2+}$ channels would also be exposed to high concentrations of drug. Since the mode of channel inhibition is through drug interaction at the cytoplasmic face of the channel and in consideration of the comparatively low $\mathrm{IC}_{50}$ values for $\mathrm{PHX}$-channel interaction (Table 1) these channels would be profoundly inhibited. This would result in catastrophic impact on heart rhythm and rate, effects that are conspicuously absent in PHX treated patients (although a heart rate lowering effect of PHX in other species has been reported $\left.^{115,116}\right)$.

Cellular accumulation could however feasibly occur via a mechanism that involves PHX binding to cytoplasmic moieties which would allow the drug to partition against its concentration gradient (Figure 2B). It is important to note though that in these circumstances, high levels of intracellular accumulation would not translate into high levels of drug concentration, and the levels of 'free' PHX in the cytoplasm would be low (Figure 2B). It is possible though that low levels of 'free' PHX in the cytoplasm, which would predominantly be in the cationic form (see above), would still be sufficient to modulate surface membrane ion channel activity (Table 1).

There is evidence of preferential association of PHX with phospholipid membranes, particularly those characterized by regional 'charge' gradients (e.g. $\mathrm{H}^{+}$gradients across 
mitochondrial and lysosomal membranes $)^{59,71,117}$ which may contribute to intra-cellular localization of very high drug concentrations at these organelles. Such a mechanism could also conceivably lead to cellular 'trapping' of PHX. As to whether the protonation of PHX in the cytoplasm of the cell would lead to a buffering of $\mathrm{H}^{+}$ions and as a consequence modulate cellular $\mathrm{pH}$, we believe this to be unlikely. In our view, any effect of $\mathrm{PHX}$ on $\mathrm{pH}$ normalization should remain focused on the relative balance of pyruvate-to-lactate which is dictated by the schemes outlined in Figure 1.

From its lipophilicity profile, the partitioning of PHX into membranes (especially mitochondrial membranes once it is protonated inside the cell) is likely to be rapid and it has been reported that high concentrations of drug applied extracellularly $(25 \mu \mathrm{M})$ affected metabolism and promoted cellular toxicity within $24 \mathrm{~h} .{ }^{89}$ Even more striking is the direct biochemical evidence for the decreased utilization of fatty acids (by approximately $35 \%$ ) in rat hearts perfused with $2 \mu \mathrm{M}$ PHX within a one-hour experimental window. ${ }^{59}$ The timings of these effects point to either rapid cellular accumulation or alternatively, to an acute indirect modulation of metabolism (i.e. downstream from inhibition of surface-membrane ion channels).

There are two plausible scenarios in which longer-term accumulation of PHX could modulate CPT-1 and its other targets at the $\mathrm{IC}_{50} \mathrm{~S}$ described in the literature (Table 1). First, if CPT-1 and the other targets are the target for PHX binding (Figure 2C). Under these conditions one would expect marked inhibition of surface membrane ion channel fluxes and, for the reasons outlined above, this is unlikely to occur in vivo. Specifically with regards CPT-1 though, the scheme described in Figure $2 \mathrm{C}$ may seem unlikely because of the endogenous competition from the much more potent malonyl CoA and the very high $\mathrm{IC}_{50}$ of $\mathrm{PHX}(>100 \mu \mathrm{M} \text { in a } P \text {. pastoris expression system })^{49}$ (Table 1). However, PHX interacts with CPT-1 via an atypical mechanism that possibly involves interaction within the plane of the membrane (see section 4, above) and thus could reach very high concentrations in the vicinity of CPT-1. Such massively localized accumulation of PHX at CPT-1 would constitute 'active-site concentration'111 although little is known as to how this phenomena may 
influence drug-target inhibition. The idea that PHX preferentially partitions in the extravascular pericardial compartment or pericardial fat (as occurs with amiodarone) ${ }^{49}$ is not supported by Drury's study which determined very high levels of PHX accumulation in myocardial tissue obtained via biopsy of patients undergoing coronary artery bypass surgery which was presumably free of pericardial fat. ${ }^{112}$

The second scenario for chronic PHX accumulation, and in our view the most likely mechanism that reconciles the low potency of PHX for CPT-1 with its actions on this target and on other ion channels is shown in Figure 2D. In this scheme PHX distribution is heterogeneous and (1) it accumulates in the membrane, (2) it interacts directly with CPT-1 and (3) some of the drug is free in the cytoplasm as a result of an equilibrium set up between cytoplasmic binding factor(s) and the bulk hydrophilic environment. All of these distributions though are subject to saturability such that eventually all targets/binding partners would be PHX bound or associated with intracellular moieties. After dosing previously drug naïve patients at a plasma concentration of approximately $1 \mu \mathrm{M}$, concentrations of $\mathrm{PHX}$ in ventricular tissue reached over $10 \mathrm{mg} / \mathrm{kg}$ (approximately $36 \mu \mathrm{M}$ ) within 30 days of drug administration (median 8.5 days). ${ }^{112}$ Moreover, although the PHX accumulation in these tissues was directly correlated with plasma concentration of drug and length of therapy there was no evidence of saturability of uptake over the time of study. ${ }^{112}$ In a more recent follow-up, the conclusion of Chong and colleagues that PHX does exhibit saturability is not supported by their data (see ${ }^{103}$, Fig $2 A$ and B). Given these observations, it is difficult to conceive of how long-term PHX administration, even with maintenance of plasma concentrations of the drug at around $1 \mu \mathrm{M}$, would not lead to the steady accumulation of toxic levels of PHX. However, one of the authors of this article (ZY) has been treating some HF patients with $\mathrm{PHX}$ for over ten years; this chronic administration of $\mathrm{PHX}$ is well tolerated and the symptomatic improvements are substantial. Clearly, there are factors that affect PHX tolerance and accumulation that remain incompletely understood.

Finally, one commonly overlooked feature of CPT-1 is its widespread tissue distribution. CPT-1 is expressed at lower levels in the heart than in other tissues including 
kidney, liver, pancreas, lung and intestine. ${ }^{49}$ The issues considered above would presumably apply equally in these tissues and the reported patterns of hepato-, neuro- and gastrotoxicity are consistent with this idea.

\section{(7) Expert Opinion.}

In this article we have considered issues relating to the chemistry, mechanism of action, tissue accumulation and clinical benefits of PHX. An improved understanding of PHX drug safety and monitoring has underpinned its use in patients with HF and the evidence for its therapeutic efficacy in this context is strong. However, the disparate clinical endpoints following PHX administration in HF arising from distinct aetiologies (e.g. ischaemic- versus non-ischaemic HF) suggest that the mechanism of action of $\mathrm{PHX}$ is complex and not fully understood.

The more recent literature is dominated by the concept that the beneficial effects of $\mathrm{PHX}$ are due primarily to its inhibition of myocardial CPT-1. Contrary to this dogma, having reviewed all the available evidence, including key patents relating to the clinical usage of $\mathrm{PHX}$ and detailed studies of drug-target interactions, we suggest that it is very unlikely that the major effects of $\mathrm{PHX}$ are due to $\mathrm{CPT}-1$ inhibition. Furthermore, over the last twenty years or so the preoccupation with CPT-1 as the most relevant target of PHX has overshadowed a substantive body of older, but very credible evidence, for PHX affecting the extra-cardiac circulatory system. It is entirely likely that the therapeutic benefits of PHX in HF are due to combined cardiac and vascular effects (e.g. vasodilation).

The robustness of some of the statements made regarding PHX and CPT-1 inhibition is at stark odds with the limited evidence supporting such a mechanism that can be found in the literature. In a recent and detailed analysis of CPT-1 inhibitor chemistry, Ceccarelli effectively debunked the idea that perhexiline is a physiologically relevant CPT- 1 inhibitor. ${ }^{49}$ However, we cannot completely exclude the possibility that minor effects of PHX on CPT-1 underpin disproportionately large effects on myocardial function, especially since there is massive accumulation of the drug in atrial and ventricular tissue. To reconcile these 
arguments, it is plausible that the symptomatic improvements determined in HF patients are due to the fact that PHX is not a good CPT-1 inhibitor in an in vivo setting and that any clinical utility is dependent on only partial CPT-1 inhibition. Horowitz and colleagues, who first positioned PHX as an exemplar CPT-1 inhibitor ${ }^{60,71}$, have previously acknowledged this likelihood, albeit from the perspective of toxicity rather than efficacy- "the adverse reactions encountered with perhexiline and indeed those of other CPT-1 inhibitors (e.g. etomoxir) are the consequence of excessive CPT-1 and hence fatty acid metabolism inhibition". ${ }^{71}$ Like $\mathrm{PHX}$, the antianginal trimetazidine exerts multiple effects via multiple mechanisms (see e.g. ${ }^{118}$ ); it is a potent inhibitor of beta-oxidation of free fatty acids ${ }^{119}$, but only a weak CPT1 inhibitor $^{120}$, and has been shown to reduce fibrosis ${ }^{121}$ and to normalise aberrant $\mathrm{Ca}^{2+}$ handling in cardiomyocytes obtained from post-injured myocardium. ${ }^{122}$ Moreover, the finding that etomoxir, the only drug considered as a bona fide CPT-1 inhibitor by Ceccarelli and colleagues $^{49}$ evoked severe hepatoxicity ${ }^{123}$ would also suggest that appreciable inhibition of CPT-1 in vivo is not clinically useful. Thus although there is undeniable merit in developing new 'metabolic modulators', approaches that aim to develop selective CPT-1 targeted drugs with enhanced biological half-life and/or increased potency should be viewed with caution. It is also likely that targets other than CPT-1 present alternative strategies for regulating myocardial FA fluxes. ${ }^{49,124}$

The linked nature of the composite systems involved in metabolic regulation (i.e. the complex synchronization of ion handling, metabolite sensing, substrate utilization, energy supply-and-demand) means that reconciling any effects on altered energy metabolism with the specific effects on discrete molecular targets is extremely difficult. With this in mind, the evidence that PHX effects are mediated by its actions on a multiple ion channels and other cellular components that impinge on aspects of cellular metabolism is more convincing (Table 1). In Figure 2D, we propose a scheme which considers the effects of PHX via 1) the inhibition of surface membrane ion channels via low levels of free drug in the cytoplasm and 2) accumulation in mitochondrial membranes which leads to a highly localized concentration of drug in the vicinity of CPT-1 resulting in its partial inhibition. 
1

2

3

4

5

6

7

8

9

10

11

12

13

14

15

16

17

18

19

20

21

22

23

24

25

26

27

28

29

30

31

32

33

34

35

36

37

38

39

40

41

42

43

44

45

46

47

48

49

50

51

52

53

54

55

56

57

58

59

60

In summary, we suggest that due to its physico-chemical properties, $\mathrm{PHX}$ is a drug of low potency, low specificity and low selectivity. As a result, the pleiotropic actions of PHX on a diverse range of molecular targets, some of which remain to be properly defined, contribute to its therapeutic benefit in HF. 


\section{Funding}

This research has been supported by charitable grants from the British Heart Foundation (FS/09/028/27602), the Wellcome Trust (094219/Z/10/Z), and Cardiff University (Cardiff Partnership Fund).

\section{Conflict of interest}

The author has no relevant affiliations or financial involvement with any organization or entity with a financial interest in or financial conflict with the subject matter or materials discussed in the manuscript. This includes employment, consultancies, honoraria, stock ownership or options, expert testimony, grants or patents received or pending, or royalties. 


\section{References}

Reference annotations

* of interest

** of considerable interest

1. Yancy CW, Jessup M, Bozkurt B, et al. 2013 ACCF/AHA Guideline for the Management of Heart Failure: A report of the American College of Cardiology Foundation / American Heart Association Task Force on practice guidelines. Circulation 2013;128:e240e327.

2. Tiku Owens A, Brozena SC, Jessup M. New managements strategies in heart failure. Circ Res 2016;118:480-95.

3. Braunwald E. Research advances in heart failure: a compendium. Circ Res 2013;113:633-45.

4. George $\mathrm{CH}$, Barberini-Jammaers SR, Muller CT. Refocussing therapeutic strategies for cardiac arrhythmias: defining viable molecular targets to restore cardiac ion flux. Expert Opin Ther Patents 2008;18:1-19.

5. von Leuder TG, Krum H. New medical therapies for heart failure. Nat Rev Cardiol $2015 ; 12: 730-40$.

6. Sanganalmath SK, Bolli R. Cell therapy for heart failure: a comprehensive overview of experimental and clinical studies, current challenges, and future directions. Circ Res 2013;113:810-34.

7. George $\mathrm{CH}$. Sarcoplasmic reticulum $\mathrm{Ca}^{2+}$ leak in heart failure: mere observation or functional relevance? Cardiovasc Res 2008;77:302-14.

8. George $\mathrm{CH}$, Parthimos D, Silvester NC. A network-oriented perspective on cardiac calcium signaling. Am J Physiol Cell Physiol 2012;303:C897-C910.

9. Boileau E, George $\mathrm{CH}$, Parthimos D, et al. Synergy between intercellular communication and intracellular $\mathrm{Ca}^{2+}$ handling in arrhythmogenesis. Ann Biomed Engineer 2015;43:1614-25.

URL: http://mc.manuscriptcentral.com/eotp Email: Julia.Galway-Witham@informa.coln1 
10. Antoons G, Sipido KR. Targeting calcium handling in arrhythmias. Europace 2008;10:1364-69.

11. Bers DM, Harris SP. To the rescue of the failing heart. Nature 2011;473:36-39.

12. Anderson ME. Multiple downstream proarrhythmic targets for calmodulin kinase II: moving beyond an ion channel-centric focus. Cardiovasc Res 2007;73:657-66.

13. Wehrens XHT, Marks AR. Novel therapeutic approaches for heart failure by normalizing calcium cycling. Nat Rev Drug Disc 2004;3:1-9.

14. Yano M, Yamamoto T, Ikeda Y, et al. Mechanisms of Disease: ryanodine receptor defects in heart failure and fatal arrhythmia. Nat Clin Pract Cardiovasc Med 2006;3:43-52.

**15. Ashrafian H, Horowitz JD, Frenneaux MP. Perhexiline. Cardiovasc Drug Rev 2007;25:76-97.

A key review article on the history of $\mathrm{PHX}$

16. Inglis S, Stewart S. Metabolic therapeutics in angina pectoris: history revisited with perhexiline. Eur J Cardiovasc Nurs 2006;5:176-84.

17. Lee L, Horowitz J, Frenneaux M. Metabolic manipulation in ischaemic heart disease, a novel approach to treatment. Eur Heart J 2004;25:634-41.

18. Singh S, Schwarz K, Horowitz J, et al. Cardiac energetic impairment in heart disease and the potential role of metabolic modulators: a review for clinicians. Circ Cardiovasc Genet 2014;7:720-28.

19. Chong CR, Sullivan DJ. New uses for old drugs. Nature 2007;448:645-46.

20. Ashburn TT, Thor KB. Drug repositioning: identifying and developing new uses for existing drugs. Nat Rev Drug Discov 2004;3:673-83.

21. Keiser MJ, Setola V, Irwin JJ, et al. Predicting new molecular targets for known drugs. Nature 2009;462:175-81.

22. Silvester NC, George $\mathrm{CH}$. Searching for new cardiovascular drugs: towards improved systems for drug screening? Expert Opin Drug Discov 2011;6:1155-70. 
23. Lewis KJ, Silvester NC, Barberini-Jammaers SR, et al. A new system for profiling drug-induced calcium signal perturbation in human embryonic stem cell-derived cardiomyocytes. J Biomol Screen 2015;20:330-40.

24. Fleckenstein A. Specific pharmacology of calcium in myocardium, cardiac pacemakers, and vascular smooth muscle. Ann Rev Pharmacol Toxicol 1977;17:149-66.

**25. Vaughan Williams EM. Antiarrhythmic action and the puzzle of perhexiline. London: Academic Press, 1980.

A valuable resource that documents many of the historical 'puzzles' that the present review attempts to resolve given our contemporary knowledge of PHX

26. Fleckenstein A. History of calcium antagonists. Circ Res 1983;52 (Suppl. I):3-16.

27. Spedding M. Changing surface charge with salicylate differentiates between subgroups of calcium-antagonists. Br J Pharmacol 1984;83:211-20.

28. Barry WH, Horowitz JD, Smith TW. Comparison of negative inotropic potency, reversibility, and effects on calcium influx of six calcium channel antagonists in cultured myocardial cells. Br J Pharmacol 1985;85:51-59.

29. Cole PL, Beamer AD, McGowan N, et al. Efficacy and safety of perhexiline maleate in refractory angina. A double-blind placebo-controlled clinical trial of a novel antianginal agent. Circulation 1990;81:1260-70.

30. Bleifer DJ, Bleifer SB, Okun R. Perhexiline maleate in angina pectoris: a controlled, double-blind clinical trial. Geriatrics 1972;27:109-15.

31. Burns-Cox CJ, Chandrasekhar KP, Ikram H, et al. Clinical evaluation of perhexiline maleate in patients with angina pectoris. B M J 1971;4:586-88.

32. Liberts EA, Willoughby SR, Kennedy JA, et al. Effects of perhexiline and nitroglycerin on vascular, neutrophil and platelet function in patients with stable angina pectoris. Eur $\mathrm{J}$ Pharmacol 2007;560:49-55.

33. Lyon LJ, Nevin MA, Fisch S, et al. Perhexiline maleate in treatment of angina pectoris. Lancet 1971;June:1272-74. 
34. White HD, Lowe JB. Antianginal efficacy of perhexiline maleate in patients refractory to beta-adrenoceptor blockade. Int J Cardiol 1983;3:145-55.

35. Willoughby SR, Stewart S, Chirkov YY, et al. Beneficial clinical effects of perhexiline in patients with stable angina pectoris and acute coronary syndromes are assocaited with potentiation of platelet responsiveness to nitric oxide. Eur Heart J 2002;23:1946-54.

36. Ashrafian H, Frenneaux M, Opie LH. Metabolic mechanisms in heart failure. Circulation 2007;116:434-48.

37. Ingwall JS. Energy metabolism in heart failure and remodelling. Cardiovasc Res 2009;81:412-19.

38. Neubauer S. Mechanisms of disease: the failing heart- an engine out of fuel. N Engl J Med 2007;356:1140-51.

39. Stanley WC, Recchia FA, Lopaschuk GD. Myocardial substrate metabolism in the normal and failing heart. Physiol Rev 2005;85:1093-129.

40. Tuunanen $\mathrm{H}$, Knuuti J. Metabolic remodelling in human heart failure. Cardiovasc Res 2011;90:251-57.

41. Ventura-Clapier R, Garnier A, Veksler V. Energy metabolism in heart failure. J Physiol 2004;555:1-13.

42. Doenst T, Nguyen TD, Abel ED. Cardiac metabolism in heart failure: implications beyond ATP production. Circ Res 2013;113:709-24.

43. Dass S, Holloway CJ, Cochlin LE, et al. No evidence of myocardial oxygen deprivation in nonischemic heart failure. Circ Heart Fail 2015;8:1088-93.

44. Stanley WC, Chandler MP. Energy metabolism in the normal and failing heart: potential for therapeutic interventions. Heart Fail Rev 2002;7:115-30.

45. Ma XM, Blenis J. Molecular mechanisms of mTOR-mediated translational control. Nat Rev Mol Cell Biol 2009;10:307-18.

46. Arad M, Seidman CE, Seidman JG. AMP-activated protein kinase in the heart: role during health and disease. Circ Res 2007;100:474-88. 
47. Mihaylova MM, Shaw RJ. The AMPK signalling pathway coordinates cell growth, autophagy and metabolism. Nat Cell Biol 2011;13:1016-23.

48. Shimobayashi M, Hall MN. Making new contacts: the mTOR network in metabolism and signalling crosstalk. Nat Rev Mol Cell Biol 2014;15:155-62.

${ }^{*}$ 49. Ceccarelli SM, Chomienne O, Gubler M, et al. Carnitine palmitoyltransferase (CPT) modulators: a medicinal chemistry perspective on 35 years of research. J Med Chem 2011;54:3109-52.

An outstanding and in-depth review of the medicinal chemistry of CPT-1 modulators.

50. McGarry JD, Brown NF. The mitochondrial carnitine palmitoyltransferase system: from concept to molecular analysis. Eur J Biochem 1997;244:1-14.

51. Chugai Seiyaku Kabushiki Kaisha. Heterocyclic compounds useful as malonyl-CoA decarboxylase inhibitors. US7,696,365. 2010.

52. Chugai Seiyaku Kabushiki Kaisha. Piperidine compounds useful as malonyl-CoA decarboxylase inhibitors. US7,449,482. 2008.

53. Dyck JRB, Lopaschuk GD. Malonyl CoA control of fatty acid oxidation in the ischemic heart. J Mol Cell Cardiol 2002;34:1099-109.

**54. Lee L, Campbell R, Scheuermann-Freestone M, et al. Metabolic modulation with perhexiline in chronic heart failure: a randomized, controlled trial of short-term use of a novel treatment. Circulation 2005;112:3280-88.

A seminal publication describing the symptomatic benefit of PHX treatment in heart failure

55. Abozguia K, Elliott P, McKenna W, et al. Metabolic modulator perhexiline corrects energy deficiency and improves exercise capacity in symptomatic hypertrophic cardiomyopathy. Circulation 2010;122:1562-69.

56. Beadle RM, Williams LK, Kuehl M, et al. Improvement in cardiac energetics by perhexiline in heart failure due to dilated cardiomyopathy. JACC: Heart Failure 2015;3:20211.

57. Lee ESP, Edmunds L, Fraser AG, et al. Perhexiline improves functional outcome in patients with refractory angina and heart failure. Eur J Heart Fail 2013;12:S241. 
58. Pepine CJ, Schang SJ, Bemiller CR. Effects of perhexiline on coronary hemodynamic and myocardial metabolic responses to tachycardia. Circulation 1974;XLIX:887-93.

59. Jeffery FMH, Alvarez L, Diczku V, et al. Direct evidence that perhexiline modifies myocardial substrate utilization from fatty acids to lactate. J Cardiovasc Pharmacol 1995;25:469-72.

*60. Queen Elizabeth Hospital. Methods related to the treatment of and isolation of compounds for treatment of ischaemic conditions. WO1997000678. 1997.

Patent describing the use of an assay based on CPT-1 inhibition

61. Heart Metabolics Limited. Perhexiline for treating chronic heart failure. US8,470,806. 2013.

62. Heart Metabolics Limited. Treatment of heart failure. US8,440,697. 2013.

63. University of Birmingham. Perhexiline for use in the treatment of hypertrophic cardiomyopathy (HCM). US8,697,728. 2014.

64. University Court of the University of Aberdeen. Fluoro-perhexiline compounds and their therapeutic use. WO2014184561. 2014.

65. Chirkov $\mathrm{YY}$, Holmes AS, Willoughby SR, et al. Stable angina and acute coronary syndromes are associated with nitric oxide resistance in platelets. J Am Coll Cardiol 2001;37:1851-57.

66. Hudak WJ, Lewis RE, Kuhn WL. Cardiovascular pharmacology of perhexiline. J Pharm Exp Ther 1970;137:371-82.

67. O'Hara N, Ono H, Ognuro K, et al. Vasodilating effects of perhexiline, glyceryl trinitrate, and verapamil on the coronary, femoral, renal, and mesenteric vasculature of the dog. J Cardiovasc Pharmacol 1981;3:251-68.

68. Morano I, Isac M, Bletz C, et al. Perhexiline increases calcium-activated force in skinned psoas fibres by raising calcium affinity of troponin-C. Biomed Biochim Acta 1989;48:S329-S34.

URL: http://mc.manuscriptcentral.com/eotp Email: Julia.Galway-Witham@informa.com6 
69. Kennedy JA, Beck-Oldach K, McFadden-Lewis K, et al. Effect of the anti-anginal agent, perhexiline, on neutrophil, valvular and vascular superoxide formation. Eur $\mathrm{J}$ Pharmacol 2006;531:13-19.

70. Frenneaux M. New tricks for an old drug. Eur Heart J 2002;23:1898-99.

**71. Kennedy JA, Unger SA, Horowitz J. Inhibition of carnitine palmitoyltransferase-1 in rat heart and liver by perhexiline and amiodarone. Biochem Pharmacol 1996;52:273-80. The original paper in which PHX was proposed as a CPT-1 inhibitor

72. Jackson VN, Cameron JM, Fraser F, et al. Use of six chimeric proteins to investigate the role of intramolecular interactions in determining the kinetics of carnitine palmitoyltransferase I isoforms. J Biol Chem 2000;275:19560-66.

73. Jackson VN, Cameron JM, Zammit VA, et al. Sequencing and functional expression of the malonyl-CoA-sensitive carnitine palmitoyltransferase from Drosophila melanogaster. Biochem J 1999;341:483-89.

74. Heygi B, Komaromi I, Nanasi PP, et al. Selectivity problems with drugs acting on cardiac $\mathrm{Na}^{+}$and $\mathrm{Ca}^{2+}$ channels. Curr Med Chem 2013;20:2552-71.

75. George $\mathrm{CH}$, Thomas NL, Lai FA. Ryanodine receptor dysfunction in arrhythmia and sudden cardiac death. Future Cardiol 2005;1:531-41.

*76. Mencher SK, Wang LG. Promiscuous drugs compared to selective drugs (promiscuity can be a virtue). BMC Clin Pharmacol 2005;5:3.

A thought-provoking opinion on drug pleiotropy

77. Smith BK, Perry CGR, Koves TR, et al. Identification of a novel malonyl-CoA IC50 for CPT-1: implications for predicting in vivo fatty acid oxidation rates. Biochem J 2012;448:1320.

78. Stephens TW, Higgins AJ, Cook GA, et al. Two mechanisms produce tissue-specific inhibition of fatty oxidation by oxfenicine. Biochem J 1985;227:651-60.

79. Kennedy JA, Kiosoglous AJ, Murphy GA, et al. Effect of perhexiline and oxfenicine on myocardial function and metabolism during low-flow ischemia/reperfusion in the isolated rat heart. J Cardiovasc Pharmacol 2000;36:794-801. 
*80. Patel A, Jones SA, Ferro A, et al. Pharmaceutical salts: a formulation trick or a clinical conundrum. Br J Cardiol 2009;16:281-86.

An interesting perspective on the physiological effects of counterions in pharmaceutical formulations

81. Pacanis A, Strzelecki T, Rogulski J. Effects of maleate on the content of CoA and its derivatives in rat kidney mitochondria. J Biol Chem 1981;256:13035-38.

82. Rogulski J, Pacanis A, Strzelecki T, et al. Effects of maleate on carbohydrate metabolism in rats. Am J Physiol 1976;230:1163-67.

83. Tuncel AT, Ruppert T, Wang B-T, et al. Maleic acid- but not structurally related methylmalonic acid- interrupts energy metabolism by impaired calcium homeostasis. PLoS One 2015;10:e0128770.

84. Yin X, Dwyer J, Langley SR, et al. Effects of perhexiline-induced fuel switch on the cardiac proteome and metabolome. J Mol Cell Cardiol 2013;55:27-30.

85. Gehmlich K, Dodd MS, Allwood JW, et al. Changes in the cardiac metabolome caused by perhexiline treatment in a mouse model of hypertrophic cardiomyopathy. Mol Biosyst 2015;11:564.

86. Gatto Jr GJ, Ao Z, Kearse MG, et al. NADPH oxidase-dependent and -independent mechanisms of reported inhibitors of reactive oxygen generation. J Enzyme Inhib Med Chem 2013;28:95-104.

87. Unger SA, Kennedy JA, McFadden-Lewis K, et al. Dissociation between metabolic and efficiency effects of perhexiline in normoxic rat myocardium. J Cardiovasc Pharmacol $2005 ; 46: 849=55$.

88. Shah RR, Oates NS, Idle JR, et al. Impaired oxidation of debrisoquine in patients with perhexiline neuropathy. BMJ 1982;284:295-99.

89. Deschamps D, DeBeco V, Fisch C, et al. Inhibition by perhexiliene of oxidative phosphorylation and the B-oxidation of fatty acids: possible role in pseudoalcoholic liver lesions. Hepatology 1994;19:948-61.

URL: http://mc.manuscriptcentral.com/eotp Email: Julia.Galway-Witham@informa.com8 
90. Shah RR. Can pharmacogenetics help rescue drugs withdrawn from market? Pharmacogenomics 2006;7:889-908.

91. Singlas E, Goujet MA, Simon P. Pharmacokinetics of perhexiline maleate in anginal patients with and without peripheral neuropathy. Europ J Clin Pharmacol 1978;14:195-201.

92. Afzal Mir M, Kafetzakis EM. Assessment of perhexiline maleate in angiographically proven intractable angina: a double-blind trial. Am Heart J 1978;96:350-54.

93. Morgan MY, Reshef R, Shah RR, et al. Impaired oxidation of debrisoquine in patients with perhexiline liver injury. Gut 1984;25:1057-64.

94. Fromenty B, Pessayre D. Inhibition of mitochondrial beta-oxidation as a mechanism of hepatoxicity. Pharmac Ther 1995;67:101-54.

95. Cooper RG, Evans DAP, Price AH. Studies on the metabolism of perhexiline in man. Eur J Clin Pharmacol 1987;32:569-76.

96. Gonzales FJ, Skoda RC, Kimura S, et al. Characterization of the common genetic defect in humans deficient in debrisoquine metabolism. Nature 1988;331:442-46.

97. Sallustio BC, Westley IS, Morris RG. Pharmacokinetics of the antianginal agent perhexiline: relationship between metabolic ratio and steady-state dose. $\mathrm{Br} \mathrm{J}$ Clin Pharmacol 2002;54:107-14.

98. Gardiner SJ, Begg EJ. Pharmacogenetics, drug-metabolizing enzymes, and clinical practice. Pharm Rev 2006;58:521-90.

99. Amoah AG, Gould BJ, Parke DV. Single-dose pharmacokinetics of perhexiline administered orally to humans. J Chromatogr 1984;305:401-09.

100. Amoah AG, Gould BJ, Parke DV, et al. Further studies on the pharmacokinetics of perhexiline maleate in humans. Xenobiotica; the fate of foreign compounds in biological systems 1986;16:63-68.

101. Cooper RG, Evans DAP, Whibley EJ. Polymorphic hydroxylation of perhexiline maleate in man. J Med Genet 1984;21:27-33.

102. Hutt AJ, Tan SC. Drug chirality and its clinical significance. Drugs 1996;52 Suppl. $5: 1-12$ 
103. Chong CR, Drury NE, Licari G, et al. Stereoselective handling of perhexiline: implications regarding accumulation within the human myocardium. Eur J Clin Pharmacol 2015;71:1485-91.

104. Gould BJ, Amoah AG, Parke DV. Stereoselective pharmacokinetics of perhexiline. Xenobiotica 1986;16:491-502.

105. Inglis SC, Herbert MK, Davies BJ, et al. Effect of CYP2D6 metabolizer status on the disposition of the (+) and (-) enantiomers of perhexiline in patients with myocardial ischaemia. Phamacogenet Genomics 2007;17:305-12.

106. Licari G, Sallustio BC, Somogyi AA, et al. The enantiomers of the myocardial metabolic agent perhexiline display divergent effects on hepatic energy metabolism and peripheral neural function in rats. Global Heart 2014;9:e272.

107. Adelaide Research \& Innovation Pty Ltd; Central Adelaide Local Health Network Inc.; Itek Ventures Pty Ltd. Uses of (-)-perhexiline. WO2014036603. 2014.

108. Horowitz JD, Morris PM, Drummer $\mathrm{OH}$, et al. High-performance liquid chromatography assay of perhexiline maleate in plasma. J Pharmacol Sci 1981;70:320-22. 109. Horowitz JD, Sia STB, Macdonald PS, et al. Perhexiline maleate treatment for severe angina pectoris- correlations with pharmacokinetics. Int J Cardiol 1986;13:219-29.

110. Stewart S, Voss DW, Northey DL, et al. Relationship between plasma perhexiline concentration and symptomatic status during short-term perhexiline therapy. Ther Drug Monit 1996;18:635-39.

111. Tylutki Z, Polak S. Plasma vs. heart tissue concentration in humans - literature data analysis of drugs distribution. Biopharm Drug Dispos 2015;36:337-51.

**112. Drury NE, Licari G, Chong C-R, et al. Relationship between plasma, atrial and ventricular perhexiline concentrations in humans: insights into factors affecting myocardial uptake. Br J Clin Pharmacol 2013;77:789-95.

A paper describing the remarkable levels of PHX that accumulate in cardiac tissue. 
113. Seki S, Kobayashi M, Itagaki S, et al. Contribution of organic anion transporting polypeptide OAT2B1 to amiodarone accumulation in lung epithelial cells. Biochim Biophys Acta $2009 ; 1788: 911-17$.

114. Barry WH, Horowitz JD, Smith TW. Comparison of negative inotropic potency, reversibility, and effects on calcium influx of six calcium channel antagonists in cultured myocardial cells. Br J Pharmacol 1985;85:51-59.

115. Matsuo S, Cho YW, Aviado DM. Pharmacology of a new antianginal drug: perhexiline. II. Heart rate and transmembrane potential of cardiac tissue. Chest 1970;58:581-85.

116. Yokoyama S, Konishi T, Matsuyama E, et al. Effects of perhexiline maleate on the refractory periods of isolated atrial muscle and atrioventricular node of the rabbit. $\mathrm{J}$ Cardiovasc Pharmacol 1982;4:26-31.

117. Shacoori V, Leray G, Guenet L, et al. Inhibition of $\left(\mathrm{Na}^{+}, \mathrm{K}^{+}\right)-\mathrm{ATPase}$ and $\mathrm{Mg}^{++}-$ ATPase by a lysosomotropic drug: perhexiline maleate. Res Commun Chem Pathol Pharmacol 1988;59:161-72.

118. Chrusciel P, Rysz J, Banach M. Defining the role of trimetazidine in the treatment of cardiovascular disorders: some insights on its role in heart failure and peripheral artery disease. Drugs 2014;74:971-80.

119. Kantor PF, Lucien A, Kozak R, et al. The antianginal drug trimetazidine shifts cardiac energy metabolism from fatty acid oxidation to glucose oxidation by inhibiting mitochondrial long-chain 3-ketoacyl coenzyme A thiolase. Circ Res 2000;86:580-88.

120. Kennedy JA, Horowitz JD. Effect of trimetazidine on carnitine palmitoyltransferase-1 in the rat heart. Cardiovasc Drugs Ther 1998;12:359-63.

121. Liu X, Gai Y, Liu F, et al. Trimetazidine inhibits pressure overload-induced cardiac fibrosis through NADPH oxidase-ROS-CTGF pathway. Cardiovasc Res 2010;88:150-58. 122. Meng D, Feng L, Chen $\mathrm{X}-\mathrm{J}$, et al. Trimetazidine improved $\mathrm{Ca}^{2+}$ handling in isoprenaline-mediated myocardial injury of rats. Exp Physiol 2006;91:591-601. 
*123. Holubarsch CJF, Rohrbach M, Karrasch M, et al. A double-blind randomized multicentre clinical trial to evaluate the efficacy and safety of low doses of etomoxir in comparison with placebo in patients with moderate congestive heart failure: the ERGO (etomoxir for the recovery of glucose oxidation) study. Clin Sci 2007;113:205-12.

Paper giving foundation to the concept that CPT-1 inhibitors with improved specificity/selectivity may not be clinically useful

124. Luiken JJFP, Niessen HEC, Coort SLM, et al. Etomoxir-induced partial carnitine palmitoyltransferase 1 (CPT-1) inhibition in vivo does not alter cardiac long-chain fatty acid uptake and oxidation rates. Biochem J 2009;419:447-55.

125. Rampe D, Wang Z, Fermini B, et al. Voltage- and time-dependent block by perhexiline of $\mathrm{K}^{+}$currents in human atrium and in cells expressing a $\mathrm{Kv1.5}$-type cloned channel. J Pharmacol Exp Ther 1995;274:444-49.

126. Perrin MJ, Kuchel PW, Campbell TJ, et al. Drug binding to the inactivated state is necessary but not sufficient for high-affinity binding to human ether-a-go-go-related gene channels. Mol Pharmacol 2008;74:1443-52.

127. Walker BD, Valenzuela SM, Singleton CB, et al. Inhibition of HERG channels stably expressed in a mammalian cell line by the antianginal agent perhexiline maleate. $\mathrm{Br} \mathrm{J}$ Pharmacol 1999;127:243-51.

128. Grima M, Velly J, Decker N, et al. Inhibitory effects of some cyclohexylaralkylamines related to perhexiline on sodium influx, binding of $\left[{ }^{3} \mathrm{H}\right]$ batrachotoxinin $\mathrm{A}$ 20-alpha-benzoate and $\left[{ }^{3} \mathrm{H}\right]$ nitrendipine and on guinea pig left atria contractions. Eur J Pharmacol 1988;147:173-85.

129. Kluppel MLW, Vieira Lopes LC, Silveira O, et al. Possible mechanism of action of perhexiline maleate on heart mitochondria. Biochem Pharmacol 1976;25:2383-86. 
1

2

3

4

5

6

7

8

9

10

11

12

13

14

15

16

17

18

19

20

21

22

23

24

25

26

27

28

29

30

31

32

33

34

35

36

37

38

39

40

41

42

43

44

45

46

47

48

49

50

51

52

53

54

55

56

57

58

59

60

\begin{tabular}{lllll}
\hline Rank & Target & $\mathrm{IC}_{50}$ & Experimental system & Ref. \\
order of & $(\mu \mathrm{M})$ & & \\
potency & & \\
\hline
\end{tabular}

Table 1. Rank order of PHX inhibitory potency.

URL: http://mc.manuscriptcentral.com/eotp Email: Julia.Galway-Witham@informa.com3 
$\mathrm{K}_{\mathrm{v}} 1.5, \mathrm{~K}^{+}$channel carrying the ultra-rapid delayed rectifier current $\left(\mathrm{IK}_{\mathrm{ur}}\right)$; HEK, human embryonic kidney; $\mathrm{CHO}$, Chinese hamster ovary; HERG, $\mathrm{K}^{+}$channel encoded by the human ether-a-go-go related gene that carries the rapid delayed rectifier current $\left(\mathrm{IK}_{\mathrm{r}}\right)$. 
Table 2. Chemical names, structures and logP values of $\mathrm{Ca}^{2+}-, \mathrm{Na}^{+}-, \mathrm{K}^{+}$-channel and CPT inhibitors.

\begin{tabular}{|c|c|c|c|c|}
\hline Drug & IUPAC name & Structure & $\log P$ & $\begin{array}{l}\text { Primary } \\
\text { target }\end{array}$ \\
\hline Verapamil & $\begin{array}{l}\text { (RS)-2-(3,4- } \\
\text { dimethoxyphenyl)-5-\{[2- } \\
\text { (3,4-dimethoxyphenyl)ethyl] } \\
\text { (methyl)amino\}-2-(propan-2- } \\
\text { yl)pentanenitrile }\end{array}$ & & 3.8 & $\begin{array}{l}\text { L-type } \mathrm{Ca}^{2+} \\
\text { channel }\end{array}$ \\
\hline Nifedipine & $\begin{array}{l}\text { 3,5-dimethyl 2,6-dimethyl-4- } \\
\text { (2-nitrophenyl)-1,4- } \\
\text { dihydropyridine-3,5- } \\
\text { dicarboxylate }\end{array}$ & & 2.2 & $\begin{array}{l}\text { L-type } \mathrm{Ca}^{2+} \\
\text { channel }\end{array}$ \\
\hline Disopyramide & $\begin{array}{l}\text { (RS)-4-[bis(propan-2- } \\
\text { yl)amino]-2-phenyl-2- } \\
\text { (pyridin-2-yl)butanamide }\end{array}$ & & 2.6 & $\mathrm{Na}^{+}$channels \\
\hline Procainamide & $\begin{array}{l}\text { 4-amino- } N-[2- \\
\text { (diethylamino)ethyl] } \\
\text { benzamide }\end{array}$ & & 0.9 & $\mathrm{Na}^{+}$channels \\
\hline Flecainide & $\begin{array}{l}\text { (RS)- } N \text {-(piperidin-2- } \\
\text { ylmethyl)-2,5-bis }(2,2,2- \\
\text { trifluoroethoxy) } \\
\text { benzamide }\end{array}$ & & 3.8 & $\mathrm{Na}^{+}$channels \\
\hline Etomoxir & $\begin{array}{l}\text { ethyl 2-[6-(4- } \\
\text { chlorophenoxy)hexyl] } \\
\text { oxirane-2-carboxylate }\end{array}$ & & 4.5 & CPT \\
\hline Perhexiline & $\begin{array}{l}\text { 2-(2,2-dicyclohexylethyl) } \\
\text { piperidine }\end{array}$ & & 6.2 & See Table 1 \\
\hline Oxfenicine & $\begin{array}{l}\text { (2S)-2-amino-2-(4- } \\
\text { hydroxyphenyl)acetic acid }\end{array}$ & & 0.2 & СРТ? \\
\hline Dofetilide & $\begin{array}{l}N-[4-(2-\{[2-(4- \\
\text { methanesulfonamidophenyl) } \\
\text { ethyl](methyl)amino }\} \\
\text { ethoxy)phenyl]methanesulfo } \\
\text { namide }\end{array}$ & & & $\mathrm{K}^{+}$channels \\
\hline Amiodarone & $\begin{array}{l}\{2-[4-(2-\text { butyl-1- } \\
\text { benzofuran-3- } \\
\text { carbonyl)-2,-6- } \\
\text { diidophenoxy]ethyl\} } \\
\text { diethylamine }\end{array}$ & & 7.6 & $\mathrm{~K}^{+}$channels \\
\hline
\end{tabular}

URL: http://mc.manuscriptcentral.com/eotp Email: Julia.Galway-Witham@informa.com5 


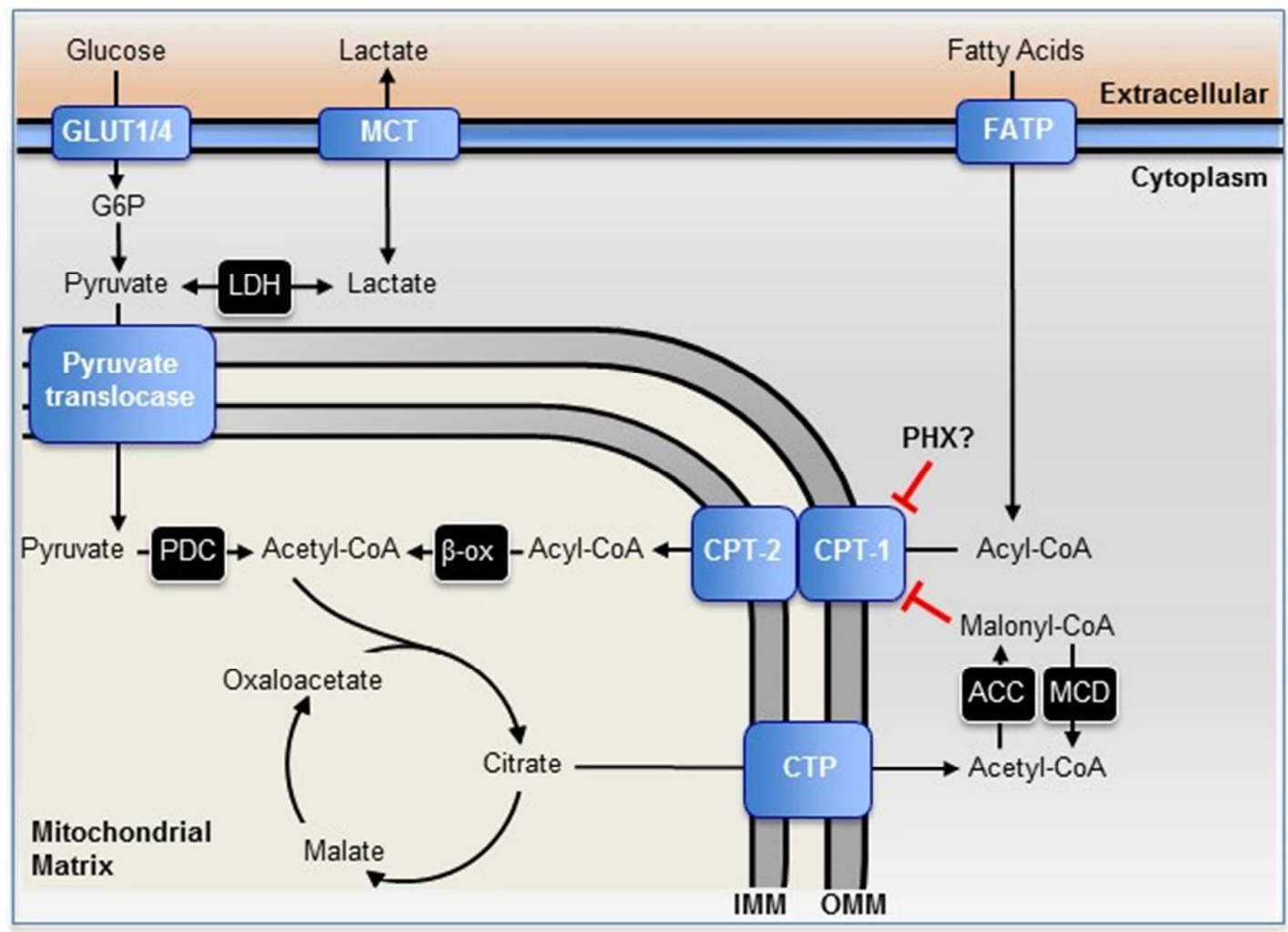

Figure 1. Endogenous inhibition of CPT-1 by malonyl-CoA

Studies using ${ }^{13} \mathrm{C}$-radiolabelled etomoxir as a probe for CPT distribution revealed that in the heart, CPT-1 is expressed to higher levels than CPT2 ${ }^{50}$ This raises the possibility that not all CPT1 is 'paired' with CPT2 as is depicted here. CPT-1B is the predominant cardiac isoform and is more sensitive to malonyl co-A inhibition than $\mathrm{CPT}-1 \mathrm{~A}\left(\mathrm{IC}_{50}\right.$ of $0.03 \mu \mathrm{M}$ vs. $0.3-1 \mu \mathrm{M}$, respectively $)^{49}$.

GLUT, glucose transporter; G6P, glucose-6-phosphate; LDH, lactose dehydrogenase; FATP, fatty acid transporter protein; MCT, monocarboxylase transporter; PDC, pyruvate dehydrogenase complex, $\beta$-ox, $\beta$-oxidation; CPT-1, carnitine palmitoyltransferase 1 ; CPT-2, carnitine palmitoyltransferase 2; CTP, citrate transporter protein; ACC, acetyl-CoA carboxylase; MCD, malonyl-CoA decarboxylase; IMM, inner mitochondrial membrane; OMM, outer mitochondrial membrane. 
A

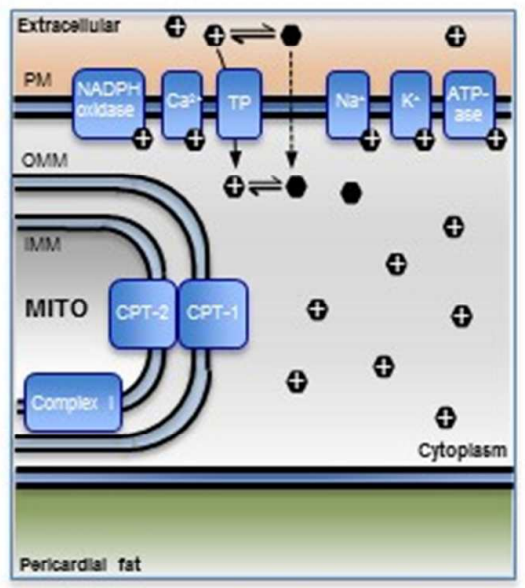

C

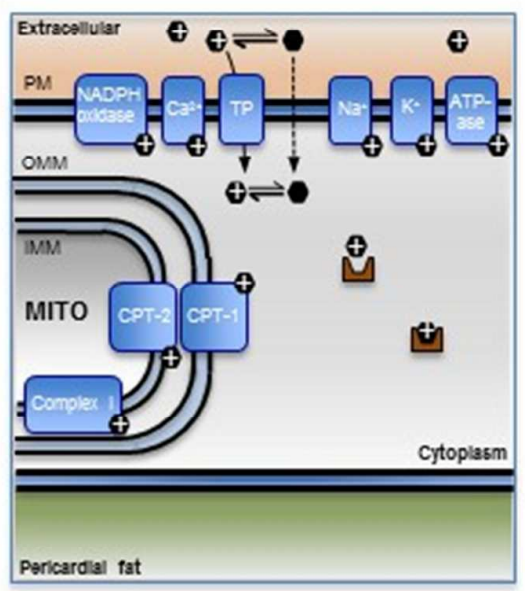

B

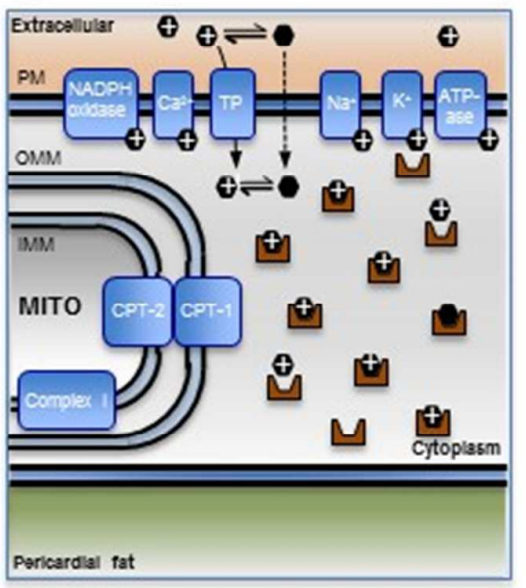

D

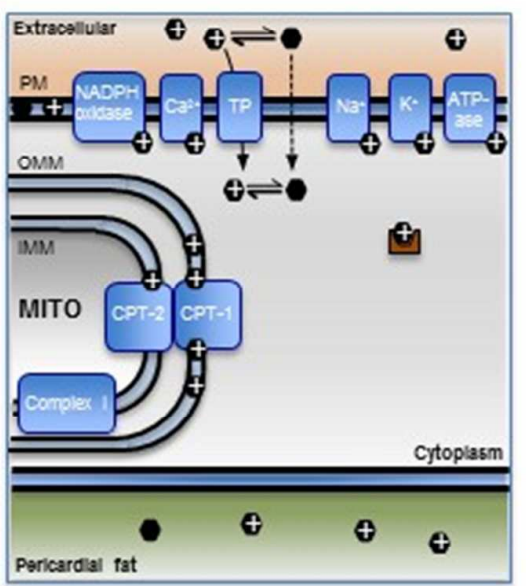

- $\operatorname{PHX}$ (cationic)

- PHX (neutral)

$M$ Binding protein

\section{Figure 2. Modes of cellular accumulation of PHX}

At pH7.4 approximately $99.9 \%$ of $\mathrm{PHX}$ would exist in the cationic form in equilibrium with approximately $0.1 \%$ as the neutral species. As described in section 5 , organic ion transporter proteins (TP) probably play an important role in the active uptake and intracellular accumulation of $\mathrm{PHX}$, as has been described for amiodarone. ${ }^{113}$ 
(A) Increased cytoplasmic [PHX] and high intracellular concentrations of 'free' (unbound) $\mathrm{PHX}$ would not be possible under equilibrium conditions if plasma $[\mathrm{PHX}]$ was maintained at much lower levels.

(B) Cellular accumulation of $\mathrm{PHX}$ could occur if $\mathrm{PHX}$ bound with reasonably high affinity to a cytoplasmic target / binding partner.

(C) Selective accumulation of PHX by direct binding to its reported targets (see Table 1).

(D) Heterogeneous distribution of PHX via partitioning of neutral and cationic species of drug into mitochondrial membranes which promotes high localized concentrations around CPT-1. Some $[\mathrm{PHX}]$ in the cytoplasm available to interact with surface membrane ion channels and, over time, accumulate in pericardial fat. 